\title{
Serum zinc level and tissue ZIP4 expression are related to the prognosis of patients with stages I-III colon cancer
}

\author{
Xin $W_{u^{1}}$, Han $W^{2}$, Liyang Liu ${ }^{1}$, Guanghui Qiang ${ }^{1}$, Jianwei Zhu ${ }^{3}$ \\ ${ }^{1}$ Department of General Surgery, the Affiliated Nanjing Jiangbei Hospital of Nantong University, Nanjing, China; ${ }^{2}$ Department of General Surgery, \\ the Affiliated Hospital of Nantong University, Nantong, China; ${ }^{3}$ Department of Gastrointestinal Surgery, the Affiliated Hospital of Nantong \\ University, Nantong, China \\ Contributions: (I) Conception and design: X Wu, H Wu, J Zhu; (II) Administrative support: J Zhu; (III) Provision of study materials or patients: X \\ Wu, H Wu, L Liu, G Qiang; (IV) Collection and assembly of data: X Wu, H Wu, L Liu, G Qiang; (V) Data analysis and interpretation: X Wu, H \\ Wu; (VI) Manuscript writing: All authors; (VII) Final approval of manuscript: All authors. \\ Correspondence to: Jianwei Zhu. Department of Gastrointestinal Surgery, the Affiliated Hospital of Nantong University, 20 Xisi Road, Nantong, \\ China. Email: usazhujianwei@aliyun.com.
}

Background: It has been reported that serum Zinc (Zn) and tissue ZRT, IRT-like protein 4 (ZIP4) are involved in the oncogenesis of several cancers. However, the relationship between them and the prognosis of colon cancer is unclear.

Methods: This was a prospective study including 116 patients with stages I-III colon cancer. The level of serum $\mathrm{Zn}$ was measured using a flame atomic absorption spectrometer. The expressions of ZIP4 in cancer tissues were measured using western blot and normal colon tissues from healthy volunteers were used as a control. The primary outcome was 2-year survival and secondary outcomes included the incidences of locoregional recurrence and distant metastasis.

Results: The average level of serum $\mathrm{Zn}$ in participants was $856.0 \pm 322.5 \mu \mathrm{g} / \mathrm{L}$. Kaplan-Meier survival curves showed that patients with $\mathrm{Zn}<856.0 \mu \mathrm{g} / \mathrm{L}$ had a significantly higher incidence of distant metastasis $(\mathrm{P}=0.02)$ and a significantly lower survival rate than those with $\mathrm{Zn} \geq 856.0 \mu \mathrm{g} / \mathrm{L}(\mathrm{P}=0.005)$. Multivariate logistic regression analysis also confirmed that having level $\mathrm{Zn}<856.0 \mu \mathrm{g} / \mathrm{L}$ was risk factor for the two outcomes. The expression of ZIP4 in cancer tissues was greatly increased as compared with the healthy control, with an average fold change of 2.4. The level of serum $\mathrm{Zn}$ was found to be positively correlated with the expression of ZIP4 in tissue. Multivariate logistic regression analysis indicated that increased expression of tissue ZIP4 was an important risk factor for locoregional recurrence $(\mathrm{P}=0.032)$, distant metastasis $(\mathrm{P}=0.039)$, and overall survival $(\mathrm{P}=0.035)$.

Conclusions: Both lower levels of serum $\mathrm{Zn}$ and increased expression of ZIP4 in tissue are associated with a poorer prognosis of patients with stages I-III colon cancer.

Keywords: Zinc; ZIP4; colon cancer; locoregional recurrence; distant metastasis; survival

Submitted Jul 02, 2020. Accepted for publication Aug 25, 2020.

doi: $10.21037 /$ tcr-20-2571

View this article at: http://dx.doi.org/10.21037/tcr-20-2571

\section{Introduction}

Colon cancer has become one of the most important cancers throughout the world in recent years. In 2018, $1,096,601$ new cases of colon cancer were reported in 185 countries, among whom 551,269 patients died (1). Surgical intervention is the most effective treatment for stages I-III colon cancer to date. However, the recurrence and metastasis of the colon cancer after surgery significantly affects patient prognosis (2). Considering the high incidence and high mortality rate of colon cancer, numerous studies have been performed to determine 
the risk factors for the prognosis for colon cancer after surgery. Major risk factors have been found including poorly differentiated colon cancer (3), large tumor size (4), low tumor purity (5), specific histological subtype (6), distant metastasis (7), age (8), and resistance to chemoradiotherapy (9). These risk factors have provided guidance for the treatment and directions for the research of colon cancer.

Recently, trace elements have drawn the increasing attention of cancer researchers. As we know, trace elements include plenty of fundamental micronutrients and are involved in many crucial biological activities, such as cell proliferation, oxidative stress, and the inflammatory response (10). Zinc ( $\mathrm{Zn})$, as a minor trace element in body, plays a crucial role in oxidative stress, DNA repair, cell differentiation, and protein synthesis (11). Moreover, $\mathrm{Zn}$ may participate in the regulation of tumor proliferation and microenvironment formation. Several studies have identified that a low level of serum $\mathrm{Zn}$ may be related to the incidence of endometrial cancer (11), prostate cancer (12), liver cancer (13), invasive urothelial bladder cancer (14), and lung cancer (15). A study from Iran demonstrated a significant decrease in the concentration of serum $\mathrm{Zn}$ in colorectal patients compared with the control group (16). Yet, the relationship between the level of serum $\mathrm{Zn}$ and the prognosis of patients with colon cancer is not clear.

The balance of intracellular $\mathrm{Zn}$ is controlled by two metal-transporter families, $\mathrm{Zn}$ transporter $(\mathrm{ZnT})$ proteins and ZRT, IRT-like proteins (ZIP) (17). ZnT proteins promote the efflux of $\mathrm{Zn}$ from cells to reduce the level of intracellular Zn, while ZIP promote the uptake of Zn from outside the cell, which increases the level of intracellular $\mathrm{Zn}$. There are several types of ZIP found in the body, from ZIP1 to ZIP14. Among all these ZIP, ZIP4 was found to be related to the proliferation, invasion, and metastasis of some cancers, including liver (18) and pancreatic cancer (19). Nevertheless, the question of whether ZIP4 plays the same role in colon cancer had not yet been answered.

This study was performed to prospectively investigate the roles of serum $\mathrm{Zn}$ and tissue ZIP4 in the prognosis of patients with stages I-III colon cancer. We present the following article in accordance with the REMARK reporting checklist (available at http://dx.doi.org/10.21037/tcr-20-2571).

\section{Methods}

\section{Patient selection}

Patients with stages I-III colon cancer admitted to the
Affiliated Nanjing Jiangbei Hospital of Nantong University and the Affiliated Hospital of Nantong University between March 2016 and June 2017 were included in this study. The study was approved by the ethics committee of the Affiliated Nanjing Jiangbei Hospital of Nantong University and the Affiliated Hospital of Nantong University Hospital. Informed consent was signed by patients or their legal representatives before inclusion in this study. This study was performed in compliance with the ethical principles of the Declaration of Helsinki (as revised in 2013). The following exclusion criteria were used: patients $<18$ or $>80$ years old; those that were pregnant; patients with distant metastasis of colon cancer; serious organ dysfunction or failure; signs of bowel perforation or obstruction requiring emergency surgery; patients having undergone surgical procedures in the past three months; patients who had not received endoscopic biopsy.

\section{Data collection}

Baseline characteristics were collected at the first admission of patients to hospital, including age, gender, body mass index (BMI), primary site of tumor, number of tumors, American joint committee on cancer (AJCC) stage, T stage, $\mathrm{N}$ stage, histologic grade, and the level of carcinoembryonic antigen (CEA). The primary site of tumor was defined as the proximal colon or distal colon. Histologic grade was defined as well differentiated, moderately differentiated, or poorly differentiated. The level of CEA was defined as positive or negative. An extra $2 \mathrm{~mL}$ blood sample was collected by skilled operators for the measurement of serum $\mathrm{Zn}$. Cancer tissues were obtained through endoscopic biopsy for the measurement of ZIP4.

\section{Measurement of serum $\mathrm{Zn}$}

Blood samples of patients were collected upon inclusion in our study. A $2 \mathrm{~mL}$ blood sample was centrifuged at $800 \mathrm{~g}$ for $10 \mathrm{~min}$ to extract serum, which was then stored at $-80{ }^{\circ} \mathrm{C}$. The level of serum $\mathrm{Zn}$ was measured using a flame atomic absorption spectrometer [PerkinElmer AAnalyst 300 (PerkinElmer, Waltham, MA, USA)], as previously reported (16). The wavelength for $\mathrm{Zn}$ was $213.9 \mathrm{~nm}$. The intra-assay coefficients of variance for the measurement of serum $\mathrm{Zn}$ were $6.6 \%$ in this study.

\section{ZIP4 measurement}

Participant colon cancer tissues were obtained through 
endoscopic biopsy and normal colon tissues were obtained from five volunteers. The expressions of ZIP4 in the sampled tissues were measured by western blot. Briefly, tissues were lysed to obtain protein lysates, from these 20 micrograms of protein was electrophoresed on $10 \%$ sodium dodecyl sulfate-polyacrylamide gel electrophoresis (SDS-PAGE) gels. Then it was transferred to PVDF membranes, which were blocked by $5 \%$ bovine serum albumin overnight at $4{ }^{\circ} \mathrm{C}$. Next, the protein was incubated with primary antibodies of anti-ZIP4 for $1 \mathrm{~h}$ at room temperature. After being washed 3 times, the membrane was incubated with horseradish peroxidase-conjugated rabbit antigoat IgG for $1 \mathrm{~h}$ at room temperature. The band intensity was analyzed using Image-pro plus analysis software (Media Cybernetics, Inc. Rockville, MD, USA) and the intensity value was converted into fold change for comparison.

\section{Outcomes}

All participants were followed up for 2 years until the end of June 2019. The primary outcome in this study was 2-year survival for patients and the secondary outcomes included the incidences of locoregional recurrence and distant metastasis. We divided all patients into two groups based on the level of serum $\mathrm{Zn}$ and the expression of ZIP4, respectively. The survival of patients and the incidences of locoregional recurrence and distant metastasis of colon cancer were compared between the two groups in order to determine the effects of serum $\mathrm{Zn}$ and ZIP4 on the patient prognosis.

\section{Statistical analysis}

All data analysis in this study was performed by SPSS 22.0 statistical software. The age and BMI of patients were reported as continuous variables, shown as means with standard deviations. Other variables were reported as categorical variables, shown as numbers with percentages. Comparisons for continuous variables and categorical variables between the two groups were performed using the student's $t$-test and the Chi-square $\left(\chi^{2}\right)$ test, respectively. Linear regression analysis was used to reveal the relationship between the level of serum $\mathrm{Zn}$ and the expression of tissue ZIP4. Multivariate logistic regression analysis was used to measure the risk factors of the outcomes. The survival of patients and the incidences of recurrence and metastasis of colon cancer during follow up were reported by KaplanMeier survival curves. The difference between the two groups was measured by log-rank test. The significance level in this study was set as 0.05 , and $\mathrm{P}<0.05$ indicated a significant difference.

\section{Results}

\section{Clinical data of enrolled patients}

Overall, 116 patients diagnosed with stages I-III colon cancer were included in this study, based on the inclusion and exclusion criteria. All patients had received surgical resection treatment. Baseline characteristics of all included patients are shown in Table 1. There were 70 male patients and 46 female patients included in this study. Their average age was $64.4 \pm 7.8$ years old and average BMI was 22.9 \pm 5.0. The tumor site of 63 patients was the proximal colon and the other 53 patients suffered from distal colon cancer. Most [106] patients in this study had a single tumor. Considering that the present study contained patients with stages I-III, we further listed the details of the AJCC Table 1. As it is shown, the majority of patients suffered stage II (48 patients, $41.4 \%$ ) and stage III (50 patients, $43.1 \%$ ) colon cancer. There were 10, 25, 55, and 26 patients who suffered colon cancer at T1, T2, T3, and T4 stage, respectively. Moreover, 66, 24, and 26 patients were diagnosed with colon cancer at the N0, N1, and N2 stage, respectively. Regarding the histologic grade, tumors were well differentiated in 28 patients, moderately differentiated in 54 patients, and poorly differentiated in 34 patients. We measured the level of serum CEA and it was found to be positive in 73 patients (62.9\%). The level of serum $\mathrm{Zn}$ was the focus of our research, and we found the average level in this study to be $856.0 \pm 322.5 \mu \mathrm{g} / \mathrm{L}$. The expressions of ZIP4 in the cancer tissues were measured by western blot, using ZIP4 expressions in healthy colon tissues as a point of reference. The expressions of ZIP4 in some of the patients and healthy volunteers are shown in Figure 1. Most patients with colon cancer had an increased expression of ZIP4, with an average fold change of $2.4 \pm 1.1$, as compared to the healthy control group. Each patient was followed up for a minimum of 2 years. During the follow up period, 13 patients were diagnosed with locoregional recurrence, 21 patients were diagnosed with distant metastases, and 20 patients had died within the 2 years (not shown).

\section{Zn level was related to the incidence of distant metastasis}

We divided all patients into two groups based on whether 
Table 1 Baseline characteristics of patients included in the study

\begin{tabular}{ll}
\hline Variables & Total \\
\hline Number & 116 \\
Gender, $\mathrm{n}(\%)$ & \\
Male & $70(60.3)$ \\
Female & $46(39.7)$ \\
Age & $64.4 \pm 7.8$ \\
BMl & $22.9 \pm 5.0$
\end{tabular}

Tumor site, $\mathrm{n}(\%)$

Proximal colon

$63(54.3)$

Distal colon

$53(45.7)$

Tumor number

Single

$106(91.4)$

Multiple

$10(8.6)$

AJCC stage, $\mathrm{n}(\%)$

I stage

$18(15.5)$

Il stage

$48(41.4)$

III stage

$50(43.1)$

T stage, $\mathrm{n}(\%)$

$\mathrm{T} 1$

$10(8.6)$

T2

$25(21.6)$

T3

55 (47.4)

$\mathrm{T} 4$

$26(22.4)$

$\mathrm{N}$ stage, $\mathrm{n}(\%)$

NO

$66(56.9)$

N1

$24(20.7)$

N2

$26(22.4)$

Histologic stage, n (\%)

Well differentiated

28 (24.1)

Moderately differentiated

$54(46.6)$

Poorly differentiated

$34(29.3)$

CEA, n (\%)

Positive

$73(62.9)$

Negative

$43(37.1)$

Level of serum $\mathrm{Zn}, \mu \mathrm{g} / \mathrm{L}$

$856.0 \pm 322.5$

Fold change of ZIP4

$2.4 \pm 1.1$

BMI, body mass index; AJCC, American joint committee on cancer; CEA, carcinoembryonic antigen. or not the level of serum $\mathrm{Zn}$ was $>856.0 \mu \mathrm{g} / \mathrm{L}$ (Table 2). Consequently, 63 patients were divided into the group of $\mathrm{Zn} \geq 856.0 \mu \mathrm{g} / \mathrm{L}$ and 53 patients were divided into the group of $\mathrm{Zn}<856.0 \mu \mathrm{g} / \mathrm{L}$. We compared baseline characteristics between the two groups and found no significant difference between them. As expected, the level of serum $\mathrm{Zn}$ was found to be positively correlated with the expression of tissue ZIP4, according to linear regression analysis (Table 3). We used Kaplan-Meier survival curves to compare the incidence of locoregional recurrence, distant metastasis, and the survival rates of patients between the two groups as shown in Figure 2. The results showed that patients in the $\mathrm{Zn}<856.0 \mu \mathrm{g} / \mathrm{L}$ group had a significantly higher incidence of distant metastasis $(\mathrm{P}=0.02)$ and a significantly lower survival rate than those in the $\mathrm{Zn} \geq 856.0 \mu \mathrm{g} / \mathrm{L}$ group ( $\mathrm{P}=0.005)$. However, the level of serum $\mathrm{Zn}$ was shown to have had no significant effect on the incidence of locoregional recurrence.

\section{ZIP4 expression significantly affected the prognosis of patients}

We continued by dividing all patients into two groups based on whether or not fold change of ZIP4 expression was >2.4 Baseline characteristics were compared between the two groups as shown in Table 2. We found that more patients in the ZIP4 >2.4 folds change group were diagnosed to be at stage III $(\mathrm{P}=0.001)$ and more patients in the ZIP4 $\leq 2.4$ folds change group were diagnosed as at N0 stage $(\mathrm{P}=0.001)$. Similarly, Kaplan-Meier survival curves were used to compare the incidence of locoregional recurrence and distant metastasis, and the survival of patients between the two groups, as shown in Figure 3. The results indicated that the repression of ZIP4 in cancer tissues was dramatically related to the prognosis of patients with colon cancer. Patients in the ZIP4 >2.4 folds change group had a significantly higher incidence of locoregional recurrence $(\mathrm{P}=0.01)$ and distant metastasis $(\mathrm{P}=0.01)$, and a significantly lower survival rate than those in the ZIP4 $\leq 2.4$ folds change group $(\mathrm{P}=0.002)$.

\section{risk factors of three outcomes}

Lastly, we measured the risk factors of the three outcomes using multivariate logistic regression analysis as shown in Table 4. It was found that $\mathrm{T}$ stage, $\mathrm{N}$ stage, and histologic grade were significant risk factors for all three outcomes. Age, $\mathrm{Zn}<856.0 \mu \mathrm{g} / \mathrm{L}$, and ZIP4 $>2.4$ folds change all acted 


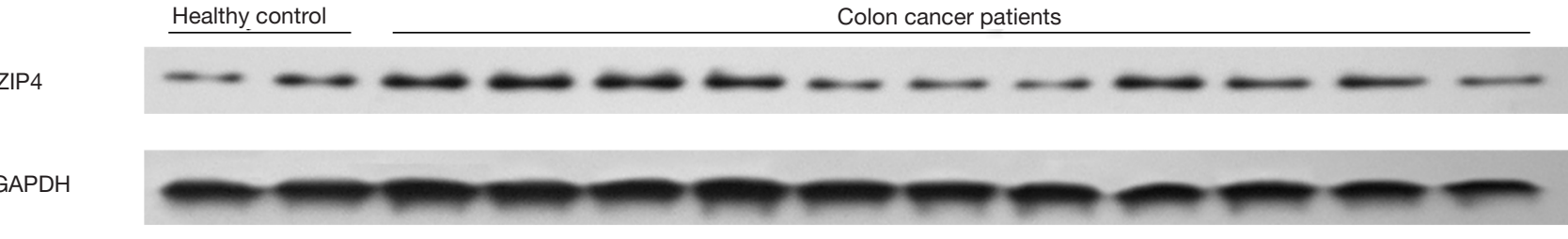

Figure 1 Representative figure for the expressions of tissue ZIP4 in healthy volunteers and patients with stages I-III colon cancer. GAPDH was used as the loading control.

as crucial risk factors for distant metastasis and overall survival in this study. Additionally, a reading of ZIP4 >2.4 folds change was found to increase the risk of locoregional recurrence.

\section{Discussion}

Trace elements play an important role in the human body, these include iron, iodine, and selenium. In our study, we identified that the level of serum $\mathrm{Zn}$ was decreased in patients with colon cancer, and that it was associated with the prognosis of patients with stages I-III colon cancer. As a crucial regulator of $\mathrm{Zn}$ in body, the expression of ZIP4 in cancer tissues was also found to affect the patients' survival rate. To the best of our knowledge, this was the first study to investigate the effect that ZIP4 has on the prognosis of colon cancer. The results derived from this study are promising in terms of deepening of our knowledge of oncogenesis and providing assistance in the future treatment of colon cancer.

Several studies have identified that low levels of serum $\mathrm{Zn}$ are a risk factor for many kinds of cancer $(11,13-15,20)$, including colon cancer (16). Our study further identified that the low level of serum $\mathrm{Zn}$ is risk factor of the prognosis of colon cancer. Zinc is necessary for DNA synthesis and cell proliferation, and is an essential part of transcription factors and regulatory enzymes (11). The proliferation of cancer cells is also dependent on increased level of intracellular $\mathrm{Zn}$. In our study, the increased expression of tissue ZIP4 was positively correlated with reduced levels of serum $\mathrm{Zn}$, which confirmed that cancer cells had a strong demand for $\mathrm{Zn}$ from the outer microenvironment. Jouybari et al. performed a meta-analysis and also found that the level of $\mathrm{Zn}$ was elevated in breast cancer tissues (21). Our study showed that raised levels of serum $\mathrm{Zn}$ may enhance the ability of colon cancer to metastasize and lead to patient death as shown in our study.

However, the mechanism how $\mathrm{Zn}$ affects cell proliferation and metastasis is not so clear. Some evidence has shown that hypoxia-inducible factor 1 (HIF-1) and vascular endothelial growth factor (VEGF) may be in the downstream pathway of $\mathrm{Zn}$. It has been reported that $\mathrm{Zn}$ could reduce the expression of HIF-1 and prevent the activation of VEGF in prostate cancer cell lines (22). However, $\mathrm{Zn}$ was reported by another study to raise the expression of HIF-1 in the same cell lines (23). The contrast in these findings may be explained by the difference in concentration of $\mathrm{Zn}$ used in the two studies. Chen et al. revealed a $U$-shaped relationship between serum $\mathrm{Zn}$ and the incidence of oral cancer, which meant both excess and deficiency of serum $\mathrm{Zn}$ had significant correlation with the risk of oral cancer (24). It is likely that a raised level of intracellular Zn may activate HIF-1 in colon cancer cells. The activation of HIF-1 in the tumor microenvironment triggers the expression of VEGF and hepatocyte growth factor (HGF) to induce the degradation of the extracellular matrix, and be further involved in the epithelial-mesenchymal transition (EMT) of cancer cells (25). Additionally, HIF1 could induce the metastasis of cancer cells through the activation of membrane protein CD24 (26). Most of the previous studies to date have focused on researching the relationship between $\mathrm{Zn}$ and oncogenesis in prostate cancer and breast cancer. It is imperative that future research is conducted to discover the mechanism how $\mathrm{Zn}$ affects the oncogenesis of colon cancer.

We found that ZIP4 is essential for zinc uptake in normal cells, and also plays a crucial role in the progression of colon cancer, which was similar to the findings of previous studies. Gartmann et al. reported that the expression of ZIP4 was significantly higher in hepatocellular carcinoma tissue than in the adjacent normal liver tissue (27). The expression of ZIP4 in tumor tissue was shown to be negatively correlated with survival time (27). Additionally, Xu et al. identified ZIP4 as an independent predictor postoperative recurrence in patients with hepatocellular carcinoma, as well as overall survival (18). In pancreatic cancer, ZIP4 was found to be 
Table 2 Comparisons of baseline characteristics of patients with different levels of serum zinc

\begin{tabular}{|c|c|c|c|c|c|c|}
\hline Variables & $\mathrm{Zn} \geq 856.0 \mu \mathrm{g} / \mathrm{L}$ & $\mathrm{Zn}<856.0 \mu \mathrm{g} / \mathrm{L}$ & $P$ value & ZIP4 $\leq 2.4$ folds change & ZIP4 >2.4 folds change & $P$ value \\
\hline Gender, n (\%) & & & & & & 0.40 \\
\hline Male & $37(58.7)$ & $33(62.3)$ & 0.70 & 37 (56.9) & $33(64.7)$ & \\
\hline Female & $26(41.3)$ & $20(37.7)$ & & $28(43.1)$ & $18(35.3)$ & \\
\hline BMI & $22.6 \pm 5.0$ & $23.3 \pm 4.6$ & 0.41 & $23.0 \pm 5.0$ & $22.8 \pm 5.3$ & 0.85 \\
\hline Tumor site, n (\%) & & & & & & 0.79 \\
\hline Proximal colon & $37(58.7)$ & $26(49.1)$ & 0.30 & $36(55.4)$ & $27(52.9)$ & \\
\hline Distal colon & $26(41.3)$ & $27(50.9)$ & & $29(44.6)$ & $24(47.1)$ & \\
\hline Multiple & $4(6.3)$ & $6(11.3)$ & & $6(9.2)$ & $4(7.8)$ & \\
\hline AJCC stage, $\mathrm{n}(\%)$ & & & & & & 0.001 \\
\hline I stage & $9(14.3)$ & $9(17.0)$ & 0.54 & $10(15.4)$ & $8(15.7)$ & \\
\hline II stage & $29(46.0)$ & $19(35.8)$ & & $36(55.4)$ & $12(23.5)$ & \\
\hline III stage & $25(39.7)$ & $25(47.2)$ & & $19(29.2)$ & $31(60.8)$ & \\
\hline T stage, n (\%) & & & & & & 0.02 \\
\hline $\mathrm{T} 1$ & $3(4.8)$ & 7 (13.2) & 0.17 & $2(3.1)$ & $8(15.7)$ & \\
\hline $\mathrm{T} 2$ & $13(20.6)$ & $12(22.6)$ & & $11(16.9)$ & $14(27.5)$ & \\
\hline N2 & $15(23.8)$ & $11(20.8)$ & & $13(20.0)$ & $13(25.5)$ & \\
\hline Histologic stage, n (\%) & & & & & & 0.33 \\
\hline Well differentiated & $12(19.0)$ & $16(30.2)$ & 0.19 & $13(20.0)$ & $15(29.4)$ & \\
\hline $\begin{array}{l}\text { Moderately } \\
\text { differentiated }\end{array}$ & $34(54.0)$ & $20(37.7)$ & & 34 (52.3) & $20(39.2)$ & \\
\hline Poorly differentiated & $17(27.0)$ & $17(32.1)$ & & $18(27.7)$ & $16(31.4)$ & \\
\hline CEA, n (\%) & & & & & & 0.67 \\
\hline Positive & $38(60.3)$ & $35(66.0)$ & 0.53 & $42(64.6)$ & $31(60.8)$ & \\
\hline Negative & $25(39.7)$ & $18(34.0)$ & & $23(35.4)$ & $20(39.2)$ & \\
\hline
\end{tabular}


significantly overexpressed in tumor cells and it could act as a prognostic marker for patients (28). Jin et al. detected ZIP4 as the most upregulated protein in the exosomes derived from pancreatic cancer cell lines and such exosomes enhanced proliferation, migration, and invasion abilities of the cell lines (19). Liu et al. investigated the mechanism of ZIP4 that promoted the progression of pancreatic cancer, and found that inactivation of ZIP4 increased the expression of tight junction protein ZO-1 and claudin-1, and inhibited the migration and invasion of pancreatic cancer cells (29). Research has found that cAMP-response element binding (CREB) protein signaling may be involved in the regulation of cell proliferation induced by ZIP4. It was reported by Yang et al. that ZIP4 promoted the growth of orthotopic pancreatic tumors in mice by activating CREB-regulated

Table 3 Univariate linear regression analysis of the association between the level of serum $\mathrm{Zn}$ and the expression of tissue ZIP4

\begin{tabular}{lcc}
\hline Level of serum $\mathrm{Zn}$ & $\mathrm{P}$ value & OR $(95 \% \mathrm{Cl})$ \\
\hline Fold change of ZIP4 & $<0.001$ & $-168.7(-219.3$ to -118.1$)$ \\
\hline
\end{tabular}

expression of RAB27B and further activating the 338 MAPK signaling pathway (30). Additionally, Liu et al. reported that ZIP4 could activate integrin $\alpha 3$ and $\beta 1$ by raising the expression of transcription factor ZEB1, which was responsible for the inhibition of gemcitabine transporter ENT1 (31), inducing the resistance to gemcitabine.

Some limitations existed in this study. Firstly, our study didn't include a large sample of patients considering the workload. Thus, the results in this study may be biased to some degree. Secondly, some characteristic information regarding surgical procedures were not collected due to most of our researchers not being directly involved in the surgical procedures. Finally, there may be some additional risk factors that were not considered in this study.

In conclusion, this prospective study that included 116 patients with stages I-III colon cancer revealed that lower levels of serum $\mathrm{Zn}$ were associated with an increased incidence of distant metastasis and reduced survival rate. Our study also found that the expression of ZIP4 in cancer tissue was significantly higher than in the healthy control group. Increased expression of tissue ZIP4 led to a higher incidence of locoregional recurrence and distant metastasis,
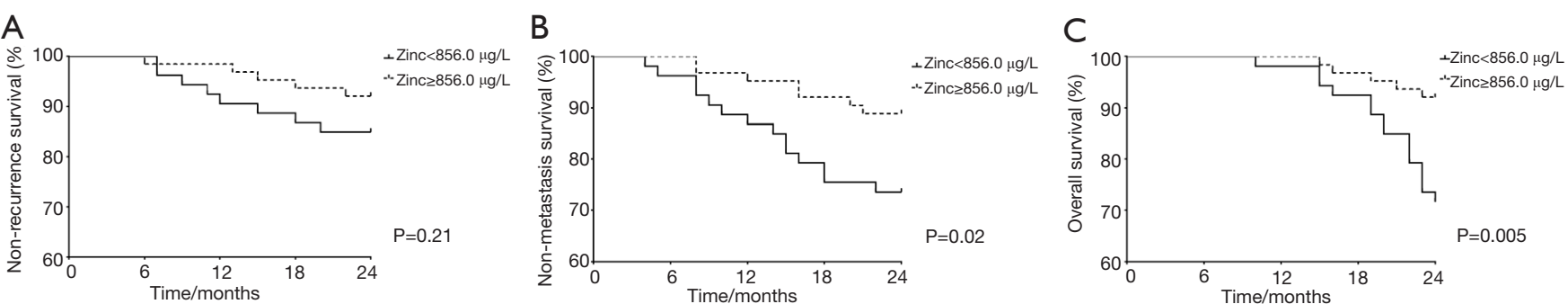

Figure 2 Kaplan-Meier curves of non-recurrence survival (A) non-metastasis survival (B) overall survival (C) comparing patients with serum level $\mathrm{Zn} \geq 856.0$ or $<856.0 \mu \mathrm{g} / \mathrm{L}$.
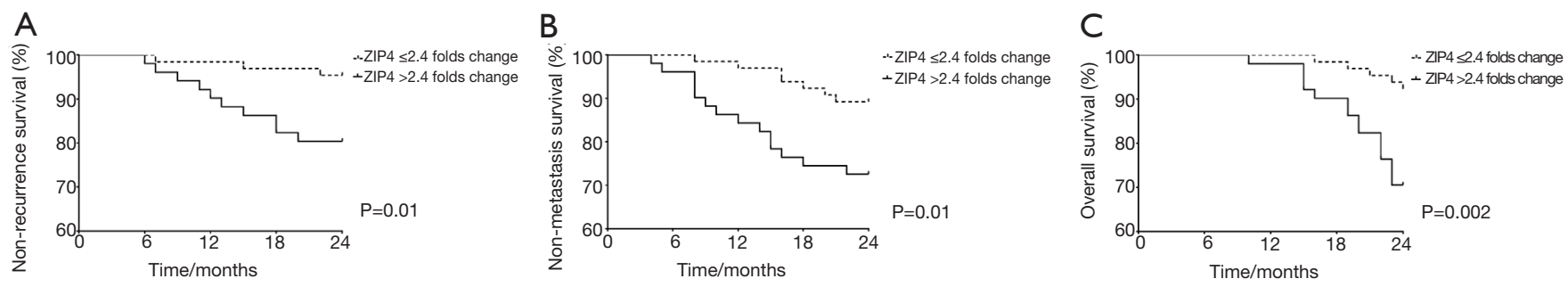

Figure 3 Kaplan-Meier curves of non-recurrence survival (A), non-metastasis survival (B), overall survival (C) comparing patients with tissue level ZIP4 $>2.4$ or $\leq 2.4$ folds change. 
Table 4 Multivariate logistic regression analysis of risk factors of outcomes in patients with stages I-III colon cancer

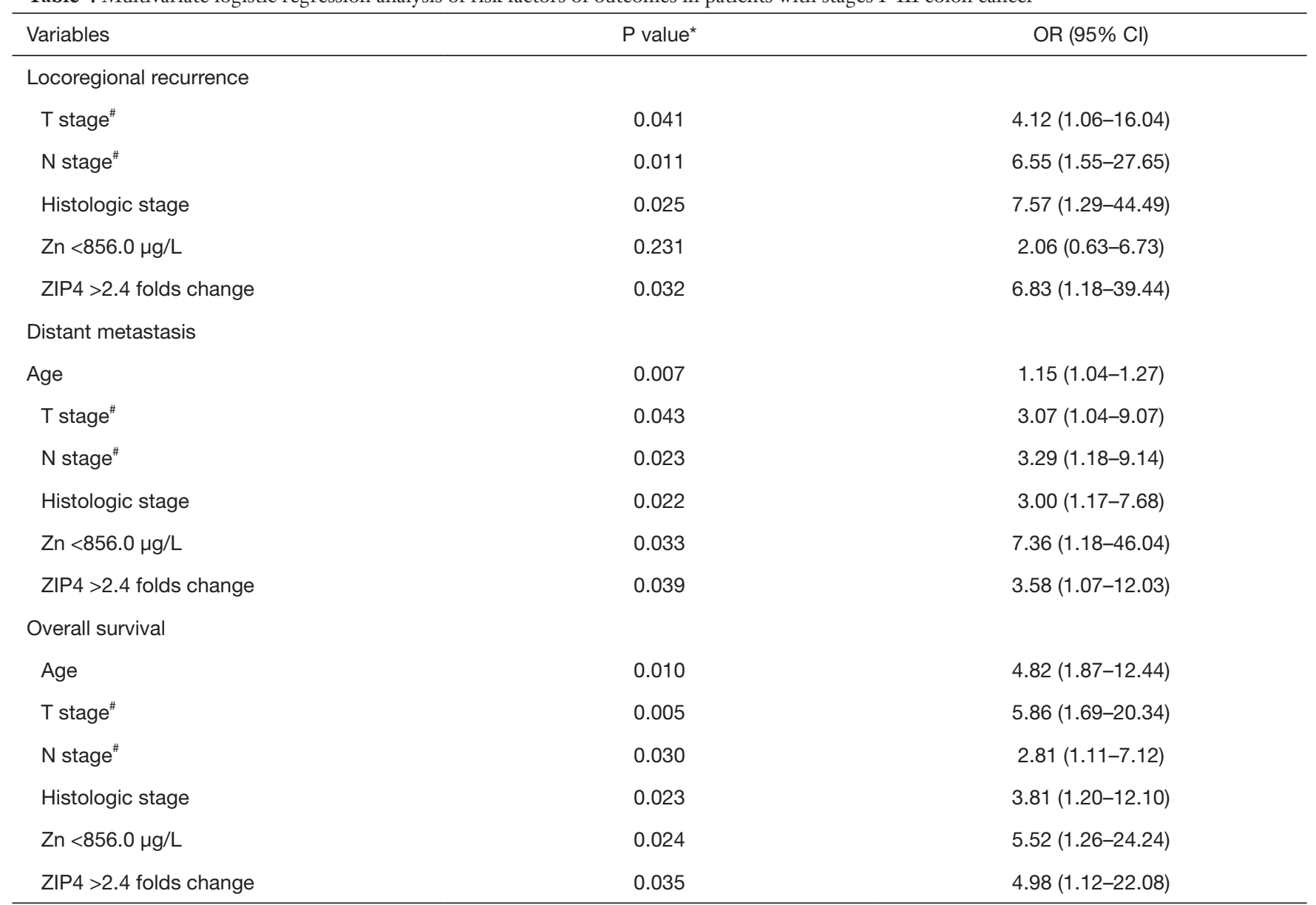

*, the analysis was adjusted by all collected risk factors such as age, gender, BMI, primary site of tumor, number of tumors, AJCC stage, $T$ stage, $\mathrm{N}$ stage, histologic stage, and CEA level. ", considering AJCC stage was defined as TNM stage, we didn't include AJCC in the multivariate regression analysis when $\mathrm{T}$ stage and $\mathrm{N}$ stage showed significant association with outcomes in the univariate analysis.

and lower survival rate during the 2-year follow up period.

\section{Acknowledgments}

Funding: This work was supported by Preventive Medicine Project of Health Committee of Jiangsu Province (y2018097).

\section{Footnote}

Reporting Checklist: The authors have completed the REMARK reporting checklist. Available at http://dx.doi. org/10.21037/tcr-20-2571

Data Sharing Statement: Available at http://dx.doi. org/10.21037/tcr-20-2571
Conflicts of Interest: All authors have completed the ICMJE uniform disclosure form (available at http://dx.doi. org/10.21037/tcr-20-2571). The authors have no conflicts of interest to declare.

Ethical Statement: The authors are accountable for all aspects of the work in ensuring that questions related to the accuracy or integrity of any part of the work are appropriately investigated and resolved. The study was approved by the ethics committee of the Affiliated Nanjing Jiangbei Hospital of Nantong University and the Affiliated Hospital of Nantong University (approval number: J20161032). Informed consent was signed by patients or their legal representatives before inclusion in this study. This study was performed in compliance with the ethical principles of the Declaration of Helsinki (as revised in 2013). 
Open Access Statement: This is an Open Access article distributed in accordance with the Creative Commons Attribution-NonCommercial-NoDerivs 4.0 International License (CC BY-NC-ND 4.0), which permits the noncommercial replication and distribution of the article with the strict proviso that no changes or edits are made and the original work is properly cited (including links to both the formal publication through the relevant DOI and the license). See: https://creativecommons.org/licenses/by-nc-nd/4.0/.

\section{References}

1. Bray F, Ferlay J, Soerjomataram I, et al. Global cancer statistics 2018: GLOBOCAN estimates of incidence and mortality worldwide for 36 cancers in 185 countries. CA Cancer J Clin 2018;68:394-424.

2. Wang L, Hirano Y, Ishii T, et al. Left colon as a novel high-risk factor for postoperative recurrence of stage II colon cancer. World J Surg Oncol 2020;18:54.

3. Patel M, McSorley ST, Park JH, et al. The relationship between right-sided tumour location, tumour microenvironment, systemic inflammation, adjuvant therapy and survival in patients undergoing surgery for colon and rectal cancer. Br J Cancer 2018;118:705-12.

4. Dai W, Mo S, Xiang W, et al. The Critical Role of Tumor Size in Predicting Prognosis for T1 Colon Cancer. Oncologist 2020;25:244-51.

5. Mao Y, Feng Q, Zheng P, et al. Low tumor purity is associated with poor prognosis, heavy mutation burden, and intense immune phenotype in colon cancer. Cancer Manag Res 2018;10:3569-77.

6. Ma Q, Song J, Chen Z, et al. Identification of potential gene and microRNA biomarkers for colon cancer by an integrated bioinformatical approach. Transl Cancer Res 2018;7:17-29.

7. Hao Y, Zhang J, Du R, et al. Impact of negative lymph nodes on colon cancer survival and exploring relevant transcriptomics differences through real-world data analyses. Ann Transl Med 2019;7:525.

8. Wegner RE, Abel S, Monga D, et al. Utilization of Adjuvant Radiotherapy for Resected Colon Cancer and Its Effect on Outcome. Ann Surg Oncol 2020;27:825-32.

9. Sun J, Wang X, Gao P, et al. Prognosis and efficiency of adjuvant therapy in resected colon signet-ring cell carcinoma. Transl Cancer Res 2018;7:1006-25.

10. Yu Z, Yu Z, Chen Z, et al. Zinc chelator TPEN induces pancreatic cancer cell death through causing oxidative stress and inhibiting cell autophagy. J Cell Physiol
2019;234:20648-61.

11. Atakul T, Altinkaya SO, Abas BI, et al. Serum Copper and Zinc Levels in Patients with Endometrial Cancer. Biol Trace Elem Res 2020;195:46-54.

12. Białkowska K, Marciniak W, Muszynska M, et al. Association of zinc level and polymorphism in MMP-7 gene with prostate cancer in Polish population. PLoS One 2018;13:e0201065.

13. Fang AP, Chen PY, Wang XY, et al. Serum copper and zinc levels at diagnosis and hepatocellular carcinoma survival in the Guangdong Liver Cancer Cohort. Int J Cancer 2019;144:2823-32.

14. Mortada WI, Awadalla A, Khater S, et al. Copper and zinc levels in plasma and cancerous tissues and their relation with expression of VEGF and HIF-1 in the pathogenesis of muscle invasive urothelial bladder cancer: a casecontrolled clinical study. Environ Sci Pollut Res Int 2020;27:15835-41.

15. Wang Y, Sun Z, Li A, et al. Association between serum zinc levels and lung cancer: a meta-analysis of observational studies. World J Surg Oncol 2019;17:78.

16. Khoshdel Z, Naghibalhossaini F, Abdollahi K, et al. Serum Copper and Zinc Levels Among Iranian Colorectal Cancer Patients. Biol Trace Elem Res 2016;170:294-9.

17. Sun P, Wang S, Jiang Y, et al. Zip1, Zip2, and Zip8 mRNA expressions were associated with growth hormone level during the growth hormone provocation test in children with short stature. Biol Trace Elem Res 2013;155:11-22.

18. Xu X, Guo HJ, Xie HY, et al. ZIP4, a novel determinant of tumor invasion in hepatocellular carcinoma, contributes to tumor recurrence after liver transplantation. Int J Biol Sci 2014;10:245-56.

19. Jin H, Liu P, Wu Y, et al. Exosomal zinc transporter ZIP4 promotes cancer growth and is a novel diagnostic biomarker for pancreatic cancer. Cancer Sci 2018;109:2946-56.

20. Saleh SAK, Adly HM, Abdelkhaliq AA, et al. Serum Levels of Selenium, Zinc, Copper, Manganese, and Iron in Prostate Cancer Patients. Curr Urol 2020;14:44-9.

21. Jouybari L, Kiani F, Akbari A, et al. A meta-analysis of zinc levels in breast cancer. J Trace Elem Med Biol 2019;56:90-9.

22. Nardinocchi L, Pantisano V, Puca R, et al. Zinc downregulates HIF-1alpha and inhibits its activity in tumor cells in vitro and in vivo. PLoS One 2010;5:e15048.

23. Ranasinghe WK, Xiao L, Kovac S, et al. The role of hypoxia-inducible factor 1alpha in determining the properties of castrate-resistant prostate cancers. PLoS One 
2013;8:e54251.

24. Chen F, Wang J, Chen J, et al. Serum copper and zinc levels and the risk of oral cancer: A new insight based on large-scale case-control study. Oral Dis 2019;25:80-6.

25. Pezzuto A, Carico E. Role of HIF-1 in Cancer Progression: Novel Insights. A Review. Curr Mol Med 2018;18:343-51.

26. Thomas S, Harding MA, Smith SC, et al. CD24 is an effector of HIF-1-driven primary tumor growth and metastasis. Cancer Res 2012;72:5600-12.

27. Gartmann L, Wex T, Grungreiff K, et al. Expression of zinc transporters ZIP4, ZIP14 and ZnT9 in hepatic carcinogenesis-An immunohistochemical study. J Trace Elem Med Biol 2018;49:35-42.

28. Xu C, Wallace MB, Yang J, et al. ZIP4 is a novel diagnostic and prognostic marker in human pancreatic cancer: a systemic comparison between EUS-FNA and surgical

Cite this article as: $\mathrm{Wu} \mathrm{X,} \mathrm{Wu} \mathrm{H,} \mathrm{Liu} \mathrm{L,} \mathrm{Qiang} \mathrm{G,} \mathrm{Zhu} \mathrm{J.}$ Serum zinc level and tissue ZIP4 expression are related to the prognosis of patients with stages I-III colon cancer. Transl Cancer Res 2020;9(9):5585-5594. doi: 10.21037/tcr-20-2571 specimens. Curr Mol Med 2014;14:309-15.

29. Liu M, Yang J, Zhang Y, et al. ZIP4 Promotes Pancreatic Cancer Progression by Repressing ZO-1 and Claudin-1 through a ZEB1-Dependent Transcriptional Mechanism. Clin Cancer Res 2018;24:3186-96.

30. Yang J, Zhang Z, Zhang Y, et al. ZIP4 Promotes Muscle Wasting and Cachexia in Mice With Orthotopic Pancreatic Tumors by Stimulating RAB27B-Regulated Release of Extracellular Vesicles From Cancer Cells. Gastroenterology 2019;156:722-734.e6.

31. Liu M, Zhang Y, Yang J, et al. ZIP4 Increases Expression of Transcription Factor ZEB1 to Promote Integrin alpha3beta1 Signaling and Inhibit Expression of the Gemcitabine Transporter ENT1 in Pancreatic Cancer Cells. Gastroenterology 2020;158:679-692.e1.

(English Language Editor: J. Jones) 